\title{
Fusion Method for Solubility and Dissolution Rate Enhancement of Ibuprofen Using Block Copolymer Poloxamer 407
}

\author{
Rohit P. Dugar, ${ }^{1}$ Bhavin Y. Gajera, ${ }^{1}$ and Rutesh H. Dave ${ }^{1,2}$
}

Received 25 September 2015; accepted 13 January 2016; published online 27 January 2016

\begin{abstract}
Aim of current research was to prepare ibuprofen-poloxamer 407 binary mixtures using fusion method and characterize them for their physicochemical and performance properties. Binary mixtures of ibuprofen and poloxamer were prepared in three different ratios (1:0.25, 1:0.5, and 1:0.75, respectively) using a water-jacketed high shear mixer. In vitro dissolution and saturation solubility studies were carried out for the drug, physical mixtures, and formulations for all ratios in de-ionized water, $0.1 \mathrm{~N}$ $\mathrm{HCl}(\mathrm{pH}=1.2)$, and phosphate buffer $(\mathrm{pH}=7.2)$. Thermal and physical characterization of samples was done using modulated differential scanning calorimetry (mDSC), X-ray powder diffraction (XRD), and infrared spectroscopy (FTIR). Flow properties were evaluated using a powder rheometer. Maximum solubility enhancement was seen in acidic media for fused formulations where the ratio 1:0.75 had 18-fold increase. In vitro dissolution studies showed dissolution rate enhancement for physical mixtures and the formulations in all three media. The most pronounced effect was seen for formulation (1:0.75) in acidic media where the cumulative drug release was $58.27 \%$ while for drug, it was $3.67 \%$. Model independent statistical methods and ANOVA based methods were used to check the significance of difference in the dissolution profiles. Thermograms from mDSC showed a characteristic peak for all formulations with $\mathrm{T}_{\text {peak }}$ of around $45^{\circ} \mathrm{C}$ which suggested formation of a eutectic mixture. XRD data displayed that crystalline nature of ibuprofen was intact in the formulations. This work shows the effect of eutectic formation and micellar solubilization between ibuprofen and poloxamer at the given ratios on its solubility and dissolution rate enhancement.
\end{abstract}

KEY WORDS: dissolution rate enhancement; fusion method; ibuprofen; poloxamer; solubility enhancement.

\section{INTRODUCTION}

Systemic bioavailability of poorly soluble drugs mainly belonging to the Biopharmaceutics Classification System (BCS) class II category has been a major challenge for the pharmaceutical industry. A prerequisite for such drugs before they get absorbed into the blood stream is their solubility in body fluids. Low aqueous solubility imposes lots of hindrances in formulation development and clinical trials in terms of optimum dissolution rate in order to achieve the required plasma concentrations, stability of formulations, etc. (1) Lots of techniques have been employed in the past for solubility enhancement like solid dispersions (2), nanosizing and micronization (3), eutectic mixtures (4), co-crystals and salt formation (5), polymorphs (6), complexation (7), surfactants and other hydrophilic polymers (8).

Fusion method for making solid dispersions and eutectic mixtures of poorly soluble drugs with hydrophilic polymers

\footnotetext{
${ }_{1}^{1}$ Arnold and Marie Schwartz College of Pharmacy and Health Sciences, Division of Pharmaceutical Sciences, Long Island University, Brooklyn, New York 11201, USA.

${ }^{2}$ To whom correspondence should be addressed. (e-mail: rutesh.dave@liu.edu)
}

has been used widely in the past for solubility enhancement and possible improvement in bioavailability of these drugs (9). It involves the use of polymers (e.g., Poloxamers (10), some grades of polyethylene glycols (11)) which melt at relatively low temperatures $\left(60-90^{\circ} \mathrm{C}\right)(12)$. This technique along with hot melt extrusion allows mixing of drug and polymer at a molecular level without the use of organic solvents. Major advantages of this method are absence of the risk of residual solvents unlike other solid dispersion techniques involving use of solvents, easy processing in terms of drying, and improved miscibility of drug and polymer at relatively low temperatures (13). In addition to enhancement of solubility, fusion method has also been employed for controlled and modified release application using hydrophobic polymers like glyceryl behenate (14), stearic acid (15), carnauba wax (16), etc. Scope of the current study was to prepare and evaluate the potential of Poloxamer 407 (Lutrol ${ }^{\circledR}$ F127 NF Prill) in improving the solubility and dissolution rate of model BCS class II drug ibuprofen.

Poloxamers are a group of non-ionic block-copolymers consisting of polyethylene oxide (PEO) and polypropylene oxide (PPO) units (-PEO-PPO-PEO-). There are different grades of Poloxamer available, and they differ in the chain length of PEO and PPO units. Poloxamer 407 is used as a 
surfactant, solubilizer, stabilizer, gel former, and also as a lubricant (17-19). It is a white, coarse prilled powder having waxy consistency with a melting point of $70^{\circ} \mathrm{C}$ and an average molecular weight of $12,600 \mathrm{~g} / \mathrm{mol}$ (20). Chemically, it consists of 101 parts of ethylene oxide units $(70 \% \mathrm{w} / \mathrm{w})$ and 56 parts $(30 \% \mathrm{w} / \mathrm{w})$ of propylene oxide units (21). Solubility and dissolution rate enhancement of drugs can be explained by reduction in surface tension and micellar solubilization in case of surfactants like Poloxamer 407 (22). Ibuprofen $(( \pm)-(\mathrm{R}, \mathrm{S})-2-4(4-i s o b u t y l p h e n y l)-p r o p i o n i c ~ a c i d)$ shown in Fig. 1, a chiral 2-arylpropionic acid derivative is a widely used non-steroidal anti-inflammatory drug and a welltolerated analgesic $(23,24)$.

Hildebrand-Scott theory of real solutions for liquid solvents and Flory-Huggins model to calculate enthalpy of mixing of drugs in polymer suggests that drugs and polymer mix in a three-step process, and each step is associated with its change in Gibb's energy which in turn depends on the change in enthalpy and entropy of the process. Stability of formulations and miscibility of drug and polymer can be predicted with these calculations. The first step is the melting of drug and polymer at their respective melting points. Secondly, the molten drug and polymer are uniformly mixed. Thirdly, the molten mixture is cooled down to room temperature to get a solid product (25-27). In case of eutectic mixtures, the melting point of the mixture is less than the individual components which means less energy is required for the first step and hence higher solubility and miscibility.

In the current study, binary mixtures of ibuprofen and Poloxamer 407 were prepared with lower levels of polymer giving a chance of higher drug loading without increasing the final formulation weight. Phase solubility, saturation solubility, and in vitro drug release studies were performed to evaluate the potential of poloxamer 407 in solubility and dissolution rate enhancement. Statistical methods were used to check the significance of difference in the dissolution profiles. Modulated differential scanning calorimetry (mDSC), X-ray powder diffraction studies (XRD), and Fourier transform infrared spectroscopy (FTIR) analysis were carried out to investigate the interaction of drug and polymer at a molecular level. Meltable polymers possess a great challenge when it comes to processing parameters during product development and powder flow properties being one of it. To evaluate the flow properties, a powder rheometer was used, and basic markers of powder flowability were evaluated.

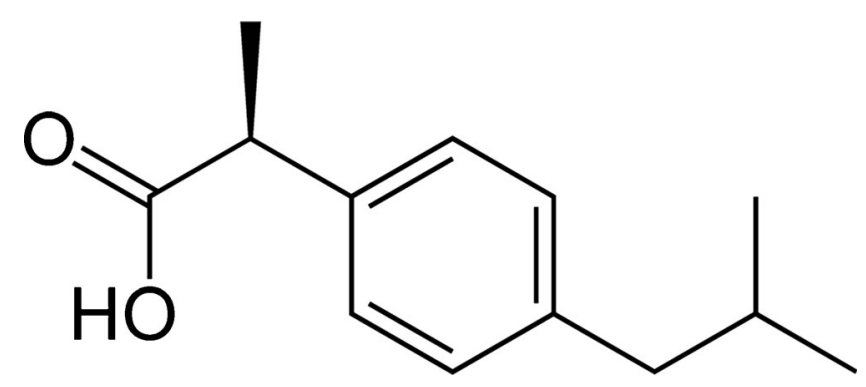

Fig. 1. Structure of ibuprofen

\section{MATERIALS AND METHODS}

\section{Materials}

Ibuprofen, a weak acid (Batch \#13 119-U13-015737), was purchased by Fagron Inc. (MN, USA) and was sieved through a 595- $\mu \mathrm{m}$ sieve (US mesh \#30) before use. Lutrol® F127 NF Prill (Lot \#WPEB612B) was kindly donated by BASF Corporation (NJ, USA). Its average particle size was $1000 \mu \mathrm{m}$.

\section{Methods}

\section{UV-Visible Spectroscopy}

Stock solution of the drug was prepared in ethanol $(100 \mu \mathrm{g} / \mathrm{ml})$, and the solution was scanned through a wavelength of 200-400 $\mathrm{nm}$ to determine the $\lambda_{\max }$ using a UV-VIS spectrophotometer (Model \# 1800, Shimadzu Scientific Instruments Inc., NJ, USA). Standard curve was prepared at the pre-determined $\lambda_{\max }$ using concentrations of 20, 40, 100, 200, 400,800 , and $1000 \mu \mathrm{g} / \mathrm{ml}$ in ethanol, and the test was performed in triplicates. Syringe filter binding studies was performed in triplicate on the above solutions by passing through a $0.45-\mu \mathrm{m}$ polytetrafluoroethylene (PTFE) filters (Acrodisc ${ }^{\circledR}$, Pall Corporation, NY, USA) and then re-analyzing to check if the dissolved drug was binding to the filters.

\section{Preparation of Physical Mixtures and Binary Fused Mixtures}

Physical mixtures were prepared for all the ratios in a turbula blender (Turbula ${ }^{\circledR}$ T2C, Glen Mills Inc., NJ, USA) at a constant speed for $10 \mathrm{~min}$. The time of blending was optimized after preliminary testing. For the current study, drug to polymer ratios selected were 1:0.25, 1:0.5, and 1:0.75 w/w, respectively. A lab-scale high shear mixer (GMX-LAB Micro®, Freund-Vector Corporation, IA, USA) was used for carrying out the fusion process in a $1-\mathrm{L}$ jacketed bowl. Jacket temperature was maintained at $75^{\circ} \mathrm{C}$ using an external water circulator (Model F25-MA, Julabo Inc., PA, USA), and fusion was carried until a product temperature of $70 \pm 1.2^{\circ} \mathrm{C}$ was attained. A lot of studies have been done over the years where the impact of process variables on the formulation properties in a high shear mixer have been observed $(28,29)$. To avoid those effects, the processing conditions were optimized by preliminary runs, and constant conditions were used for all batches. Mixing was carried out at 200 RPM (Impeller speed) and 950 RPM (Chopper speed) until fusion was completed. Mixture was cooled down in the bowl itself by rapidly circulating water at $25.0 \pm 1.0^{\circ} \mathrm{C}$ through the jacket. The solidified mixture was scrapped out, then powdered with a mill (Model L1A, FitzPatrick®, IL, USA) using a mesh of $1680 \mu \mathrm{m}$ opening (US mesh \#12). All the samples were collected and stored in tightly sealed containers in a desiccator at a temperature of $25 \pm 1.8^{\circ} \mathrm{C}$ for further analysis.

\section{Particle Size Analysis}

Particle size analysis of samples $(n=3)$ for fusion mixtures (FM) was carried out using an electromagnetic sieve shaker (Model\# LE-0765, Natoli Engineering Company Inc., MO, USA) using five standard US sieves in the size range of 
500-1410 $\mu \mathrm{m}$. Different fractions of particles were collected and weighed to determine the particle size distribution.

\section{Determination of Drug Content (Assay)}

Accurately weighed samples containing an equivalent weight of $200 \mathrm{mg}$ drug were dissolved in ethanol for both physical mixtures (PM) and FM to verify the content uniformity of samples. The solution was passed through $0.45-\mu \mathrm{m}$ syringe filters and analyzed spectrophotometrically at a $\lambda_{\max }$ of $264 \mathrm{~nm}$. All samples were done in triplicate.

\section{Saturation Solubility Studies}

For saturation solubility studies, excess amount of drug, PMs and FMs of all ratios were placed in beakers containing $40 \mathrm{ml}$ of de-ionized water, $0.1 \mathrm{~N} \mathrm{HCl}(\mathrm{pH}=1.2)$ and phosphate buffer $(\mathrm{pH}=7.2)$. Samples were stirred using a magnetic stirrer at a temperature of $26 \pm 0.5^{\circ} \mathrm{C}$ for $48 \mathrm{~h}$ and were done in triplicate. Post completion, aliquots of each sample were transferred to $15-\mathrm{ml}$ screw cap tubes and were centrifuged (Model\# GS-6R, Beckman Coulter, Inc., MA, USA) for $10 \mathrm{~min}$ at 3500 RPM maintaining a temperature of $26 \pm 0.6^{\circ} \mathrm{C}$ during centrifugation. Supernatant liquid was collected, filtered, and then analyzed spectrophotometrically at a $\lambda_{\max }$ of $264 \mathrm{~nm}$ to determine the saturation solubility.

\section{Phase Solubility Studies}

Phase solubility studies were carried out in de-ionized water as per the method described by Higuchi and Connors (30) in triplicate. Excess amount of drug was placed in beakers containing aqueous solution of increasing concentration of Poloxamer $407(0,2,4,6,8 \mathrm{mM})$. Samples were stirred using a magnetic stirrer at $26 \pm 0.5^{\circ} \mathrm{C}$ for $48 \mathrm{~h}$. After completion, aliquots of samples were centrifuged, filtered, and analyzed spectrophotometrically as described above for saturation solubility studies. The apparent stability constant $\left(\mathrm{K}_{\mathrm{s}}\right)$ value were calculated from the plot of drug solubility against surfactant concentration using Eq. 1 (31) where $S_{0}$ is drug's intrinsic solubility :

$$
K_{s}=\frac{\text { Slope }}{S_{0} *(1-\text { Slope })}
$$

\section{In Vitro Dissolution Testing}

Dissolution testing was carried out in USP dissolution apparatus type II at a speed of 50 RPM and a temperature of $37 \pm 0.2^{\circ} \mathrm{C}$ in three dissolution media i.e., de-ionized water, $0.1 \mathrm{~N} \mathrm{HCl}(\mathrm{pH}=1.2)$, and phosphate buffer $(\mathrm{pH}=7.2)$. Powdered samples having an equivalent weight of $200 \mathrm{mg}$ drug were weighed accurately, and dissolution was performed in triplicates. Similar fractions in terms of particle size (between 0 and $500 \mu \mathrm{m}$ ) were selected for all samples for testing. Five milliliters of sample was withdrawn at 5, 10, 15, 30, 45, and $60 \mathrm{~min}$ from the dissolution vessel, and equal amount of fresh media maintained at $37 \pm 0.2^{\circ} \mathrm{C}$ was replenished. Samples were filtered through PTFE filters and analyzed using spectrophotometer at a wavelength of $264 \mathrm{~nm}$.

\section{Statistical Analysis}

Model independent (time-point and pair-wise approach) and ANOVA based approaches were used to validate the significance of the observed difference in the dissolution profiles for different formulations. Model independent methods have the advantage of generating data from dissolution profiles which are not dependent on a specific parameter for fitting but only depends on the sampling times $(32,33)$. In the time-point approach, mean dissolution times $\left(\mathrm{MDT}_{60 \mathrm{~min}}\right)$ and mean dissolution rates $\left(\mathrm{MDR}_{60 \mathrm{~min}}\right)$ were calculated for each sample using the Eqs. 2 and 3, respectively.

$$
\begin{aligned}
& \mathrm{MDT}=\frac{\sum_{i=1}^{n} t_{i} \Delta M_{i}}{\sum_{i=1}^{n} \Delta M_{i}} \\
& \mathrm{MDR}=\frac{\sum_{i=1}^{n} \Delta M_{i} / \Delta t}{n}
\end{aligned}
$$

Where, $n$ is the number of sample points, $i$ is the sample number, $t_{i}$ is the midpoint time between two samples, $\Delta \mathrm{M}_{\mathrm{i}}$ is additional amount of drug released between $t_{i}$ and $t_{i-1}$, and $\Delta t$ is also the time at midpoint. For the pair-wise approach, difference $\left(f_{1}\right)$ and similarity $\left(f_{2}\right)$ factors were calculated using the Eqs. 4 and 5, respectively, as outlined in the SUPAC and IVIVC guidelines $(34,35)$. ANOVA based statistical analysis was also done using the data analysis tool pack in Microsoft Excel (Microsoft Corp., WA, USA). One-way ANOVA was done for each time point for all the dissolution data $(p<0.05)$ followed by post-hoc $t$ test to compare two groups at a time (36).

$f_{1}=\left\{\sum_{t=1}^{n}\left|R_{t}-T_{t}\right| / \sum_{t=1}^{n} R_{t}\right\} \times 100$

$f_{2}=50 \times \log _{10}\left\{\left[1+(1 / n) \sum_{t=1}^{n}\left(R_{t}-T_{t}\right)^{2}\right]^{-0.5} \times 100\right\}$

Where, $n$ is the number of sample time points, $\mathrm{R}_{\mathrm{t}}$ is the cumulative percentage drug dissolved for reference while $T_{t}$ is for the test.

\section{Powder Rheology}

Powder flow analysis is one of the important properties in relation to processability and manufacturability of formulations. Complete understanding of powder flow behavior 


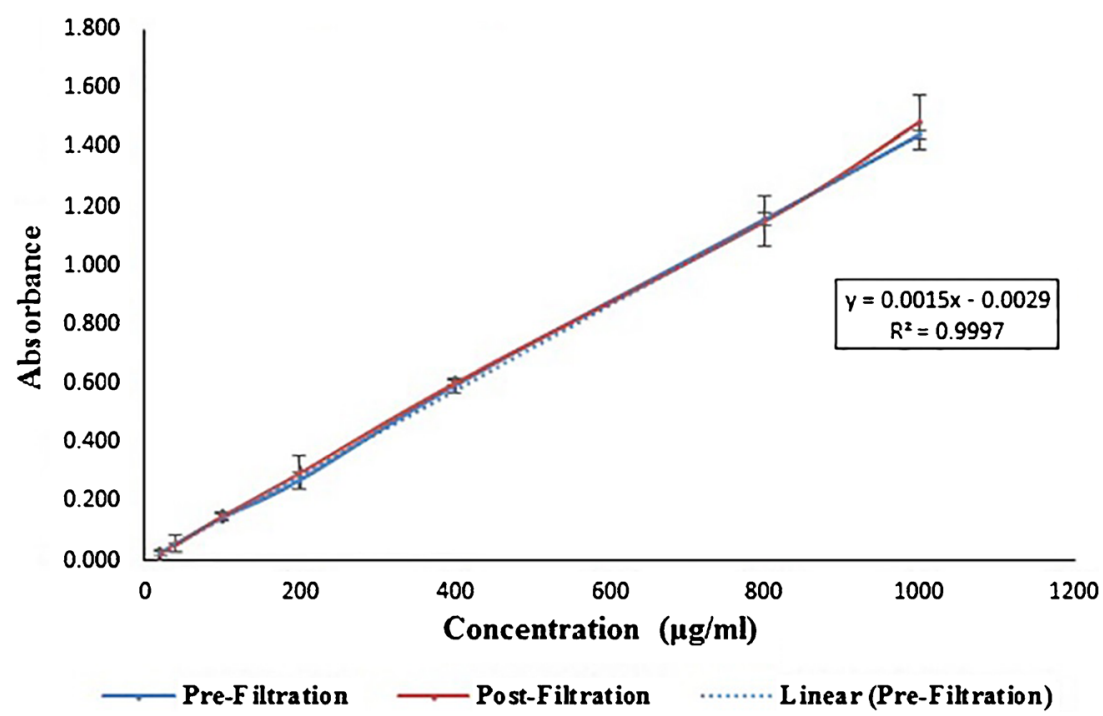

Fig. 2. Standard curve for ibuprofen using UV spectrsoscopy

requires lots of parameters to be considered. In the current study, we have measured basic energies involved in powder flow using a powder rheometer (FT4, Freeman technology, UK) i.e., basic flowability energy (BFE) and specific energy (SE). Previously, this technology has been used to understand the effect of formulation and processing variables on the rheology of powders (37). A forty-eight-millimeter stainless steel blade and $50 \mathrm{~mm} \times 160 \mathrm{ml}$ glass vessel was used for testing $(n=3)$. BFE is the work done by the downward anticlockwise motion of the rheometer blade at a tip speed of $100 \mathrm{~mm} / \mathrm{s}$ to displace constant volume of conditioned powder from top to bottom of the vessel. SE is the energy required for the upward clockwise motion of blade in an unconfined low stress environment. Volume variation among test samples for different batches was minimized using the split vessel assembly. Additionally, density measurements, Carr's indices, Angle of repose, and Hausner ratio were also evaluated. All the above tests were done in triplicates.

\section{Modulated Differential Scanning Calorimetry}

Thermal analysis was performed on all the samples using a Q100 (TA instruments, New Castle, DE) instrument with nitrogen $(50 \mathrm{ml} / \mathrm{min})$ as a purge gas. Indium was used for calibration of equipment for temperature and cell constant before performing experiments. Baseline and heat capacity calibration were also conducted by heating the empty cell and using sapphire, respectively. Hermetically sealed aluminum pans were used with pin hole on the lid to maintain a constant pressure for analysis, and a sample weight of $10 \pm 3 \mathrm{mg}$ was maintained $(n=3)$. Heating rate of $5^{\circ} \mathrm{C} / \mathrm{min}$ from 20 to $120^{\circ} \mathrm{C}$ and a modulation of $\pm 1.59^{\circ} \mathrm{C}$ every $60 \mathrm{~s}$ was used. Average melting temperatures and change in enthalpy values $\left(\Delta \mathrm{H}_{\text {melt }}\right)$ were evaluated from the thermograms. Additionally, to further evaluate the eutectic composition of ibuprofen and Poloxamer 407, different ratios of physical mixtures were prepared and analyzed.

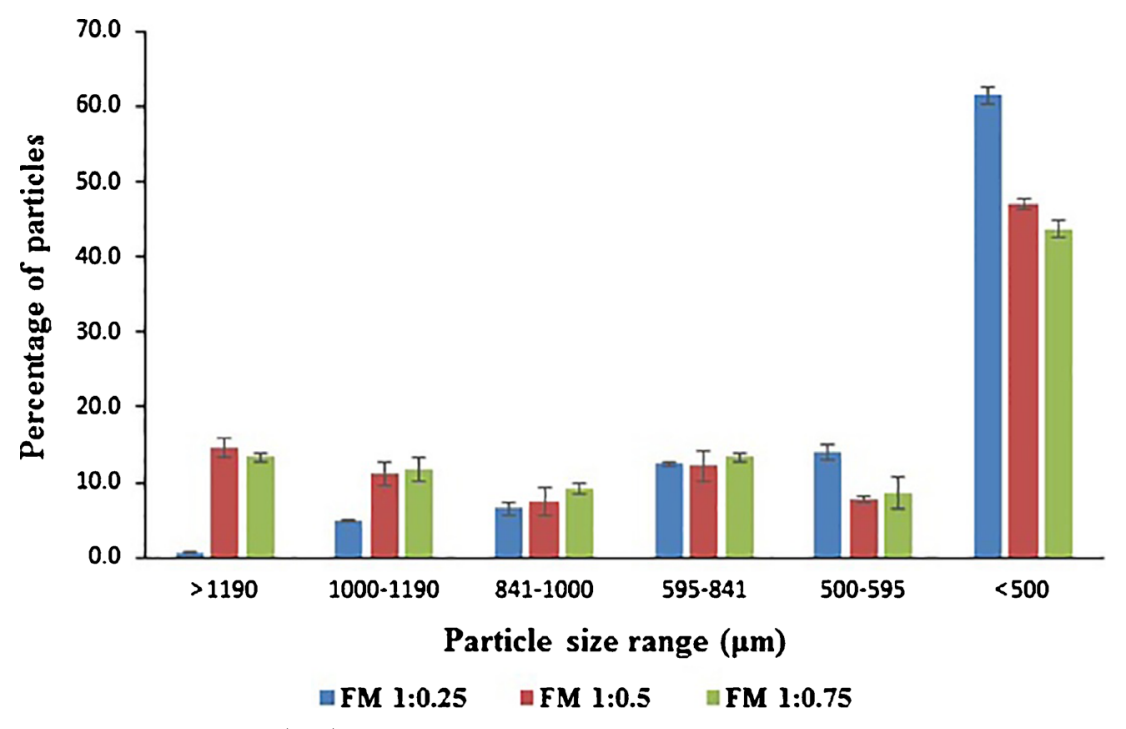

Fig. 3. Particle size analysis of fusion mixtures (FM) 


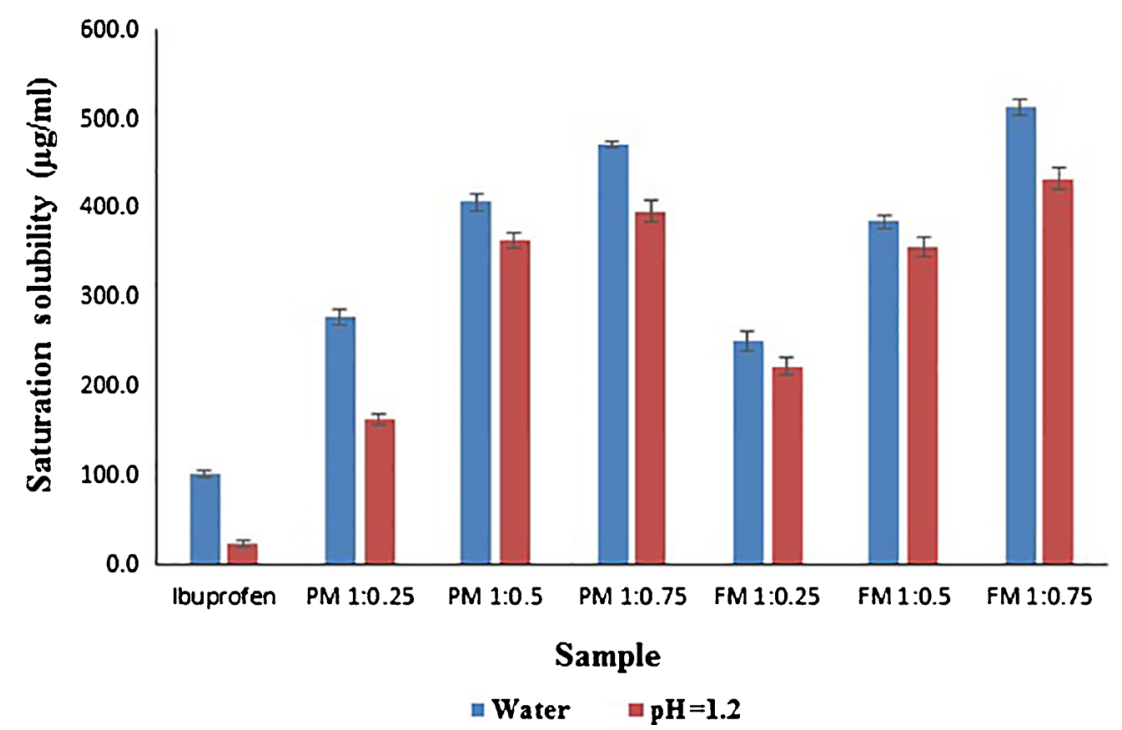

Fig. 4. Saturation solubility studies in de-ionized water and $0.1 \mathrm{~N} \mathrm{HCl}(\mathrm{pH}=1.2)$

PMs were prepared at 1:1, 1:1.5, 1:2, 1:2.5, 1:3, and 1:3.5 w/w ratios of drug and polymer corresponding to 50, 40, 33, $28.57,25$, and $22.22 \% w / w$ ibuprofen, respectively. The PMs were prepared according to the procedure described above. Phase diagram was constructed using the enthalpies of eutectic peaks $(\Delta \mathrm{H})$ against the different $\% w / w$ ratios of ibuprofen including 1:0.5 $w / w$ ratio (66\% $w / w$ ibuprofen).

\section{X-Ray Powder Diffraction Studies}

Samples were analyzed using a scanning diffractrometer (Model XI Cupertino, Advanced Diffraction System, Scintag Inc., CA, USA). Copper $\mathrm{K} \alpha$ filter was used for generating radiation at a wavelength of $1.54 \AA$ with a potential of $45 \mathrm{kV}$ and $40 \mathrm{~mA}$ current settings. Powder was pressed using a spatula on a glass slide and a bed of $1.5 \mathrm{~cm} \times 1.5 \mathrm{~cm} \times 1.5 \mathrm{~cm}$ was created. Analysis was done in the range of $5^{\circ} \leq 2 \theta \leq 40^{\circ}$ at a scan step of $0.020^{\circ}$ and time for each step being $0.5 \mathrm{~s}$.

\section{Fourier Transform Infrared Spectroscopy}

FTIR spectroscopy was done for all samples including ibuprofen, Poloxamer 407 and formulations using a Nicolet iS5 FTIR spectrophotometer with iD5 ATR diamond accessory (Thermo Fisher Scientific Inc., Madison, WI, USA). Powdered samples were placed on the diamond crystal, and knob was pressed on the sample for analysis. DTGS-KBr (deuterated tryglycine sulfate) detector was used for the study, and samples were scanned in the range of 400 to $4000 \mathrm{~cm}^{-1}$ with an average of 32 scans at a resolution of $4 \mathrm{~cm}^{-1}$.

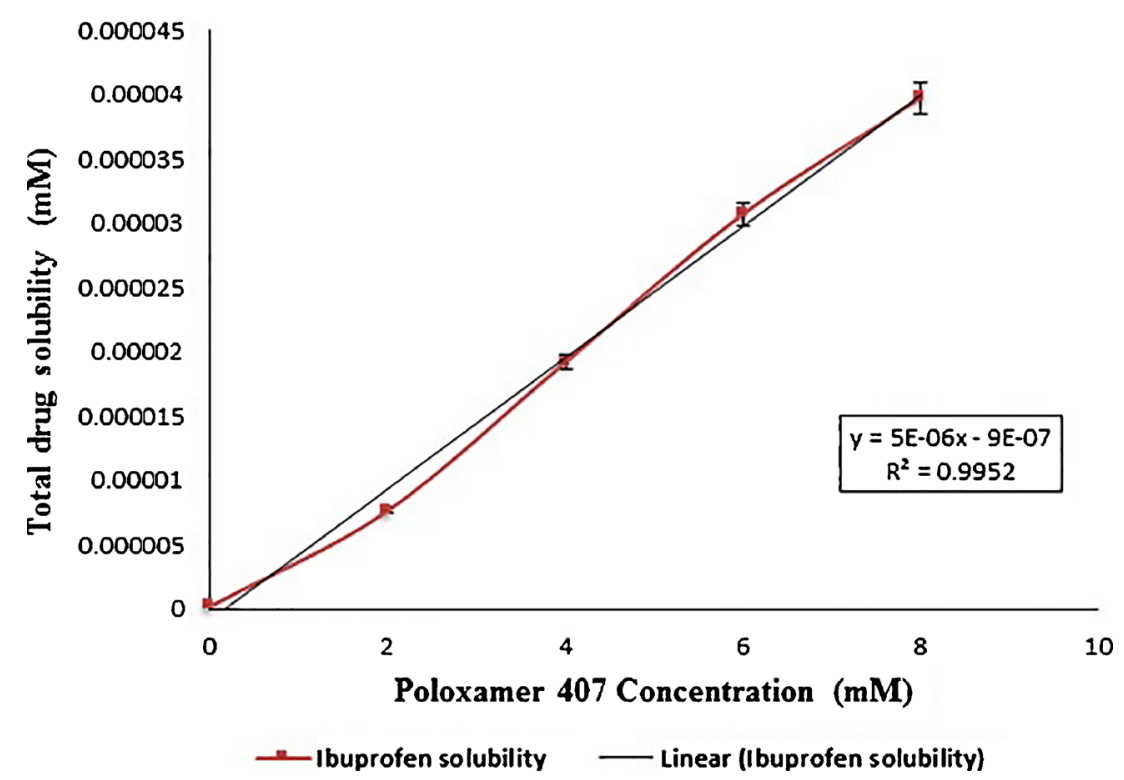

Fig. 5. Phase solubility studies 

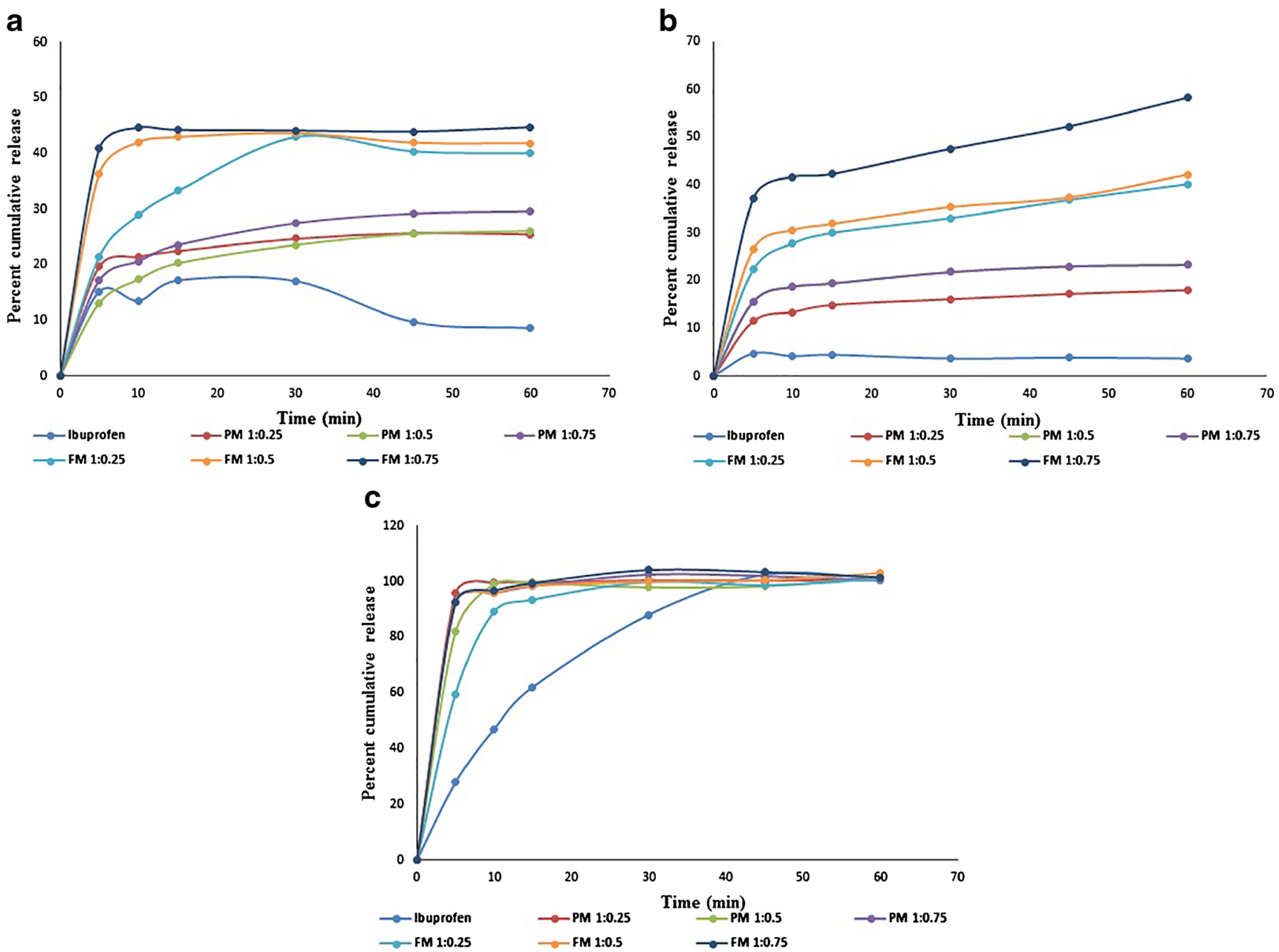

Fig. 6. In vitro dissolution studies for ibuprofen, physical mixtures (PM), and fusion mixtures (FM) in a de-ionized water; $\mathbf{b} 0.1 \mathrm{~N} \mathrm{HCl}(\mathrm{pH}=1.2)$, and $\mathbf{c}$ phosphate buffer $(\mathrm{pH}=7.2)$

Table I. Model Independent Statistical Analysis of Dissolution Profiles Between Ibuprofen, Physical Mixtures (PM) and Fusion Mixtures (FM) Sample Model independent methods ${ }^{\mathrm{a}}$

\begin{tabular}{|c|c|c|c|c|c|c|c|c|c|c|c|c|}
\hline & \multicolumn{6}{|c|}{ Time-based approach } & \multicolumn{6}{|c|}{ Pair-wise approach ${ }^{\mathrm{b}}$} \\
\hline & \multicolumn{3}{|c|}{$\mathrm{MDT}_{60 \min }(\min )$} & \multicolumn{3}{|c|}{$\operatorname{MDR}_{60 \min }\left(\% \min ^{-1}\right)$} & \multicolumn{3}{|l|}{$f_{1}$} & \multicolumn{3}{|l|}{$f_{2}$} \\
\hline & $\begin{array}{l}\text { DI } \\
\text { water }\end{array}$ & $\begin{array}{r}\mathrm{pH}= \\
1.2^{\mathrm{c}}\end{array}$ & $\begin{array}{r}\mathrm{pH}= \\
7.2\end{array}$ & $\begin{array}{l}\text { DI } \\
\text { water }\end{array}$ & $\begin{array}{r}\mathrm{pH}= \\
1.2\end{array}$ & $\begin{array}{r}\mathrm{pH}= \\
7.2\end{array}$ & $\begin{array}{l}\text { DI } \\
\text { water }\end{array}$ & $\begin{array}{r}\mathrm{pH}= \\
1.2\end{array}$ & $\begin{array}{r}\mathrm{pH}= \\
7.2\end{array}$ & $\begin{array}{l}\text { DI } \\
\text { water }\end{array}$ & $\begin{array}{r}\mathrm{pH}= \\
1.2\end{array}$ & $\begin{array}{r}\mathrm{pH}= \\
7.2\end{array}$ \\
\hline Ibuprofen & -31.05 & -2.68 & 14.39 & 0.99 & 0.30 & 2.74 & - & - & - & - & - & - \\
\hline PM 1:0.25 & 5.96 & 9.57 & 2.97 & 1.38 & 0.84 & 6.47 & 65.07 & 235.19 & 32.61 & 48.05 & 47.17 & 20.73 \\
\hline PM 1:0.5 & 10.61 & 13.95 & 4.84 & 1.04 & 0.92 & 5.85 & 173.82 & 302.23 & 558.60 & 49.36 & 41.31 & 23.15 \\
\hline PM 1:0.75 & 9.40 & 7.98 & 2.80 & 1.30 & 1.14 & 6.29 & 235.90 & 344.09 & 584.21 & 44.11 & 39.14 & 21.85 \\
\hline FM 1:0.25 & 6.71 & 12.69 & 6.33 & 1.71 & 1.69 & 4.74 & 446.97 & 587.09 & 428.77 & 31.99 & 27.41 & 29.63 \\
\hline FM 1:0.5 & 2.19 & 12.29 & 4.61 & 2.56 & 1.93 & 6.30 & 595.25 & 636.04 & 585.70 & 27.42 & 25.87 & 21.87 \\
\hline FM 1:0.75 & 3.53 & 12.78 & 2.71 & 2.80 & 2.67 & 6.31 & 644.20 & 903.16 & 597.06 & 25.76 & 18.28 & 21.54 \\
\hline
\end{tabular}

$M D T$ Mean dissolution time, $M D R$ Mean dissolution rate, $D I$ water de-ionized water

${ }^{a}$ All the parameters were calculated from mean dissolution values $(n=3)$, and hence, there is no standard deviation values

${ }^{b}$ All values were calculated with ibuprofen dissolution profile as reference

${ }^{c} 0.1 \mathrm{~N} \mathrm{HCl}(\mathrm{pH}=1.2)$ and phosphate buffer $(\mathrm{pH}=7.2)$ 
Table II. One-Way ANOVA and Post-Hoc Tests for Comparing Dissolution Profiles

\begin{tabular}{|c|c|c|c|c|c|c|}
\hline \multicolumn{7}{|c|}{ One-way ANOVA (de-ionized water) } \\
\hline Source of variation & SS & $d f$ & MS & $F$ & $P$ value & $F_{\text {critical }}$ \\
\hline Between groups $^{\mathrm{a}}$ & 3923.88 & 7 & 560.55 & 2.87 & $0.014^{*}$ & 2.21 \\
\hline \multicolumn{7}{|c|}{ One-way ANOVA $(0.1 \mathrm{~N} \mathrm{HCl}, \mathrm{pH}=1.2)$} \\
\hline Source of variation & SS & $d f$ & MS & $F$ & $P$ value & $F_{\text {critical }}$ \\
\hline Between groups & 5914.27 & 7 & 844.90 & 5.01 & $0.0003^{*}$ & 2.21 \\
\hline \multicolumn{7}{|c|}{ One-way ANOVA (phosphate buffer, $\mathrm{pH}=7.2$ ) } \\
\hline Source of variation & SS & $d f$ & MS & $F$ & $P$ value & $F_{\text {critical }}$ \\
\hline Between groups & 22726.77 & 7 & 3246.68 & 2.50 & $0.028^{*}$ & 2.21 \\
\hline \multicolumn{7}{|c|}{ Post-hoc $t$ test between PM and FM (1:0.75) } \\
\hline Media & \multirow{2}{*}{\multicolumn{2}{|c|}{ De-ionized water }} & \multicolumn{2}{|c|}{$0.1 \mathrm{~N} \mathrm{HCl}(\mathrm{pH}=1.2)$} & \multicolumn{2}{|c|}{ Phosphate buffer $(\mathrm{pH}=7.2)$} \\
\hline$P(T<=\mathrm{t})$ two-tail & & & $0.005^{*}$ & & 0.99 & \\
\hline
\end{tabular}

$S S$ sum of squares, $d f$ degree of freedom, $M S$ mean square, $F F$-ratio (calculated), $P$ value significance level, $F_{\text {critical }} F$-value based on $d f$ and level of significance

*Statistically significant $(p<0.05)$

${ }^{a}$ Analysis was performed between drug, physical mixtures (PM), and fusion mixtures (FM) for all ratios

\section{RESULTS}

\section{UV-Visible Spectroscopy}

A linear trend (pre-filtration and post-filtration) was seen at the selected $\lambda_{\max }$ of $264 \mathrm{~nm}$ as seen in Fig. 2. Equation for the straight line had a $R^{2}$ value of 0.9997 .

\section{Particle Size Analysis}

Figure 3 shows the particle size distribution of the prepared binary fusion mixtures for all the polymer ratios. Most of the particles were below the size of $500 \mu \mathrm{m}$. It was clearly seen that with the increase in the polymer ratio, there was a greater fraction of larger particles.

\section{Determination of Drug Content (Assay)}

All the samples showed between 95 and $105 \%$ of recovery of the drug and the standard deviation (SD) for the triplicate samples was below 5.0. The percent recoveries for PMs (1:0.25, 1:0.5, and 1:0.75) were 99.8, 99.4, and 97.5\% respectively whereas for FMs, they were 97.1, 104.2, and $98.4 \%$ respectively.

\section{Saturation Solubility Studies}

Saturation solubility enhancement was found for the PMs as well as the FMs for all the aqueous media used in the study as seen in Fig. 4. The effect was most pronounced in acidic media where, solubility enhancement was 18-fold for FM 1:0.75 as compared to ibuprofen. In water, it was a 5-fold increase, and in phosphate buffer, it was mere 1.15-fold. Saturation solubility for the drug itself in $\mathrm{pH} 7.2$ was around $4600 \mu \mathrm{g} / \mathrm{ml}$ whereas in $\mathrm{pH} 1.2$, it was $23 \mu \mathrm{g} / \mathrm{ml}$. Hence, data for phosphate buffer was not included in Fig. 4 just to get the scale right to give a clear picture of solubility enhancement in the other two media.

\section{Phase Solubility Studies}

Figure 5 shows the linear plot of total drug solubility with increasing surfactant concentration. $\mathrm{S}_{0}$ value was found to be $47.93 \mu \mathrm{g} / \mathrm{ml}$. Phase solubility profiles suggest that an $\mathrm{A}_{\mathrm{L}}$ type of profile is seen for the drug micellar solubilization. The apparent stability constant value was found to be $21.95 \mathrm{mM}^{-1}$.

\section{In Vitro Dissolution Testing}

Figure $6 \mathrm{a}, \mathrm{b}, \mathrm{c}$ shows the in vitro dissolution profiles in de-ionized water, $0.1 \mathrm{~N} \mathrm{HCl}(\mathrm{pH}=1.2)$ and phosphate buffer $(\mathrm{pH}=7.2)$, respectively. In acidic media, almost $58 \%$ cumulative drug release for FM 1:0.75 was encountered whereas for drug, it was only $3.67 \%$ after $60 \mathrm{~min}$. Similarly, in de-ionized water, a cumulative release of $44 \%$ for FM 1:0.75 was seen whereas for drug, it was $8 \%$ after $60 \mathrm{~min}$. There was almost $100 \%$ release for all samples including

Table III. Powder Flow Properties for Ibuprofen and Fusion Mixtures (FM)

\begin{tabular}{|c|c|c|c|c|c|c|c|}
\hline \multirow[t]{2}{*}{ Sample } & \multicolumn{7}{|l|}{ Parameters } \\
\hline & $\operatorname{BFE}(\mathrm{mJ})^{\mathrm{a}}$ & $\mathrm{SE}(\mathrm{mJ} / \mathrm{g})^{\mathrm{b}}$ & $\begin{array}{l}\text { Bulk density } \\
\qquad(\mathrm{g} / \mathrm{ml})\end{array}$ & $\begin{array}{l}\text { Tapped density } \\
\quad(\mathrm{g} / \mathrm{ml})\end{array}$ & Carr's index $(\%)$ & Hausner ratio & $\begin{array}{l}\text { Angle of repose } \\
\left(\left(^{\circ}\right)\right.\end{array}$ \\
\hline Ibuprofen & $101.10 \pm 8.23$ & $5.40 \pm 0.07$ & $0.331 \pm 0.001$ & $0.512 \pm 0.004$ & $36.06 \pm 0.59$ & $1.571 \pm 0.003$ & $43.89 \pm 0.29$ \\
\hline FM 1:0.25 & $677.99 \pm 12.35$ & $7.50 \pm 0.19$ & $0.474 \pm 0.002$ & $0.634 \pm 0.011$ & $24.42 \pm 0.26$ & $1.324 \pm 0.001$ & $32.34 \pm 0.58$ \\
\hline FM 1:0.5 & $529.07 \pm 8.57$ & $7.19 \pm 0.08$ & $0.490 \pm 0.001$ & $0.600 \pm 0.008$ & $18.64 \pm 0.85$ & $1.236 \pm 0.011$ & $29.49 \pm 1.12$ \\
\hline FM 1:0.75 & $235.28 \pm 6.59$ & $5.34 \pm 0.05$ & $0.481 \pm 0.001$ & $0.591 \pm 0.005$ & $17.60 \pm 1.02$ & $1.210 \pm 0.003$ & $27.64 \pm 0.16$ \\
\hline
\end{tabular}

${ }^{a}$ Basic flowability energy (from powder rheometer)

${ }^{b}$ Specific energy (from powder rheometer) 
a

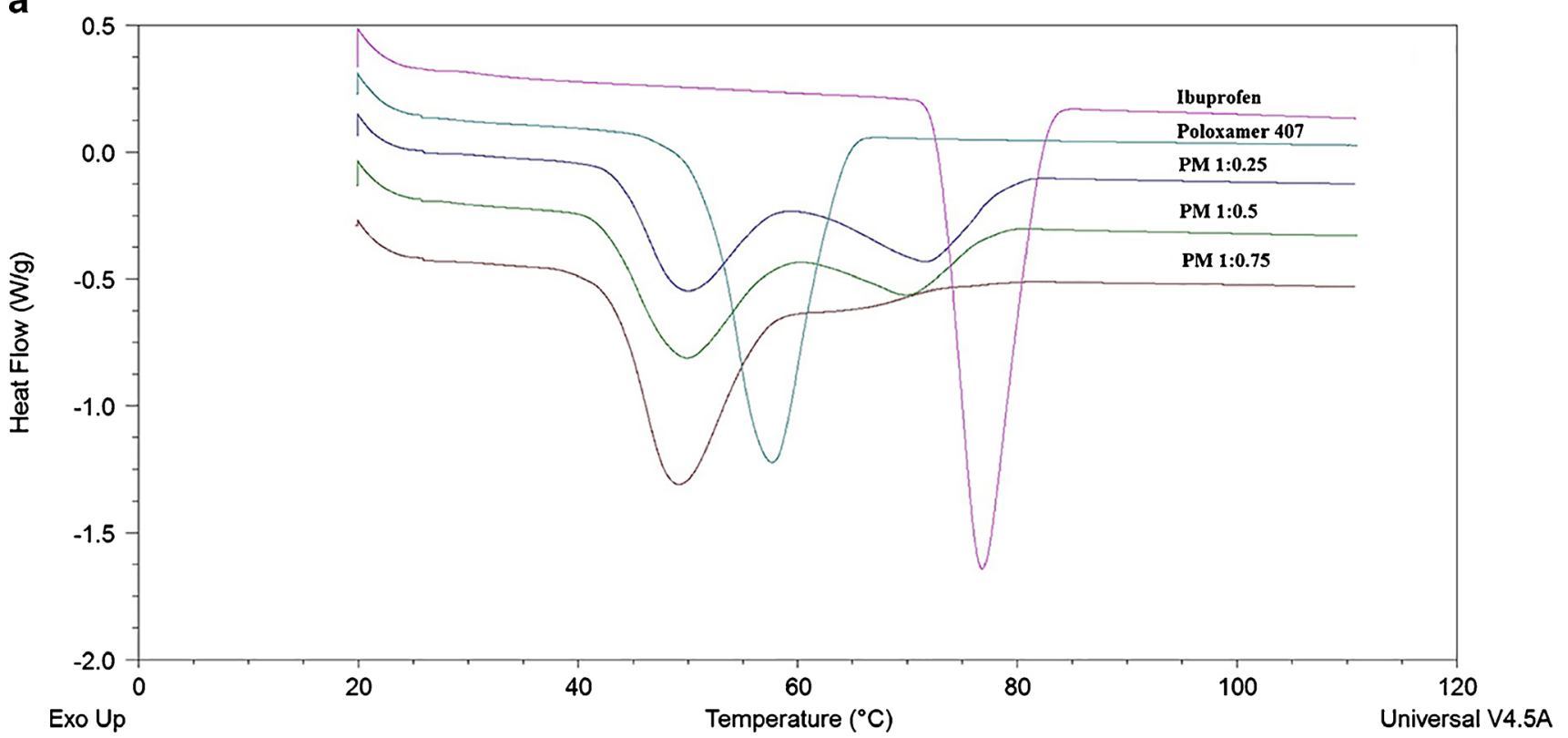

b

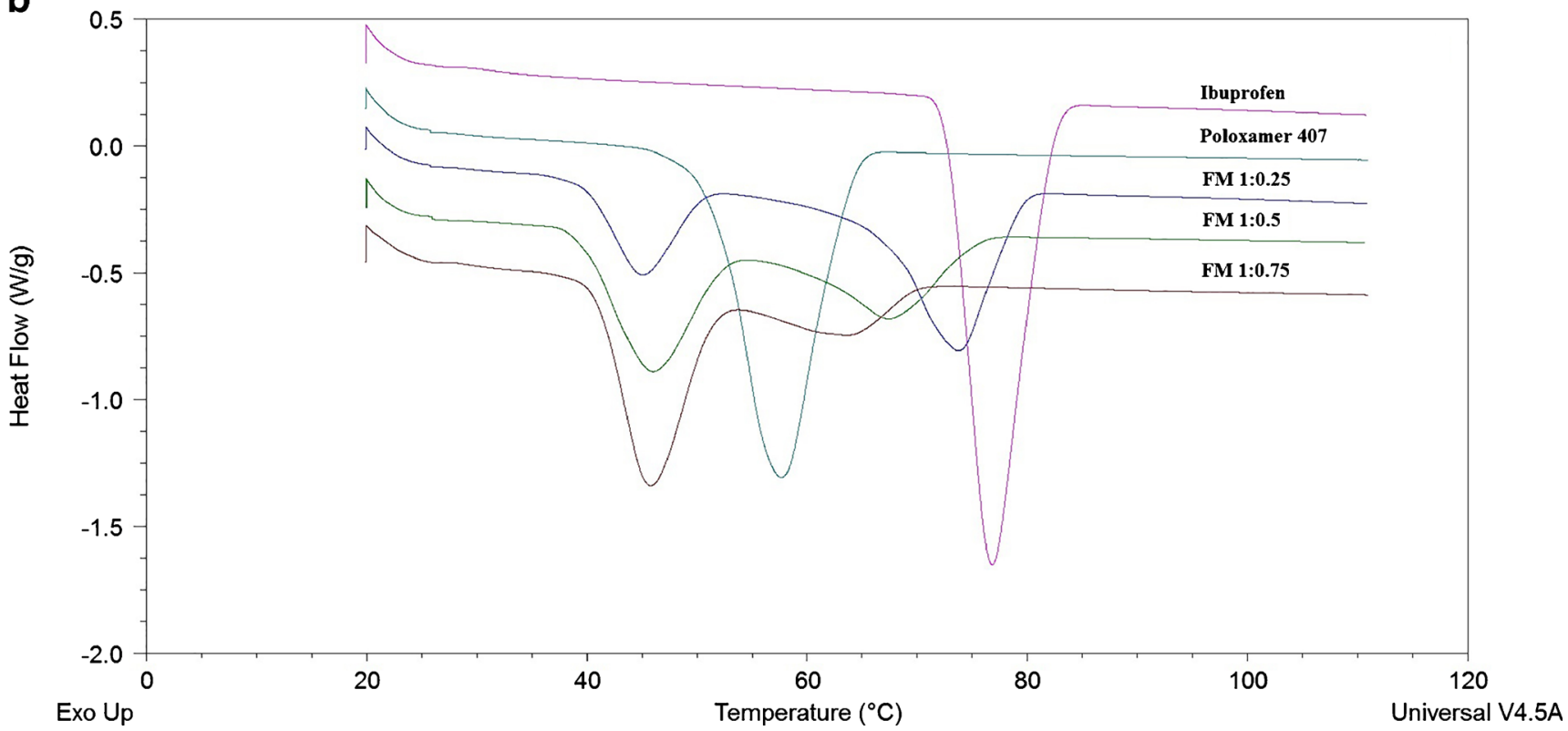

Fig. 7. Overlay of modulated differential scanning calorimeter thermograms between a ibuprofen and physical mixtures (PM); b ibuprofen and fusion mixtures (FM); $\mathbf{c}$ ibuprofen and physical mixtures (PM) for eutectic composition study; d phase diagram for ibuprofen/poloxamer 407 binary mixtures

drug in $\mathrm{pH}$ 7.2. The standard deviations are not shown in the dissolution profiles because the error bars were smaller than the markers used. Standard deviation for all the data were in the range of \pm 1.0 .

\section{Statistical Analysis}

Table I shows the values from model independent approaches applied to the in vitro dissolution profiles. A trend of decreasing $f_{2}$ values $(<50)$ and increasing $f_{1}$ values $(>15)$ going from PMs (all three ratios) to the FMs (all three ratios) was observed in all dissolution media. Table II shows the results from one-way ANOVA and post-hoc $t$ test done between different pairs of formulations. Only the between groups values were considered for analysis. Post-hoc data is only shown only for PM 1:0.75 and FM 1:0.75 (other ratios evaluated but data not shown) because it had the highest dissolution rate enhancement.

\section{Powder Rheology}

Table III shows the different parameters that were evaluated to understand the powder rheology of different formulations. BFE values decreased as the polymer content increased from an average of $678 \mathrm{~mJ}$ (FM 1:0.25) to $235 \mathrm{~mJ}$ (FM 1:0.75). The SE values were similar for all formulations. 
C

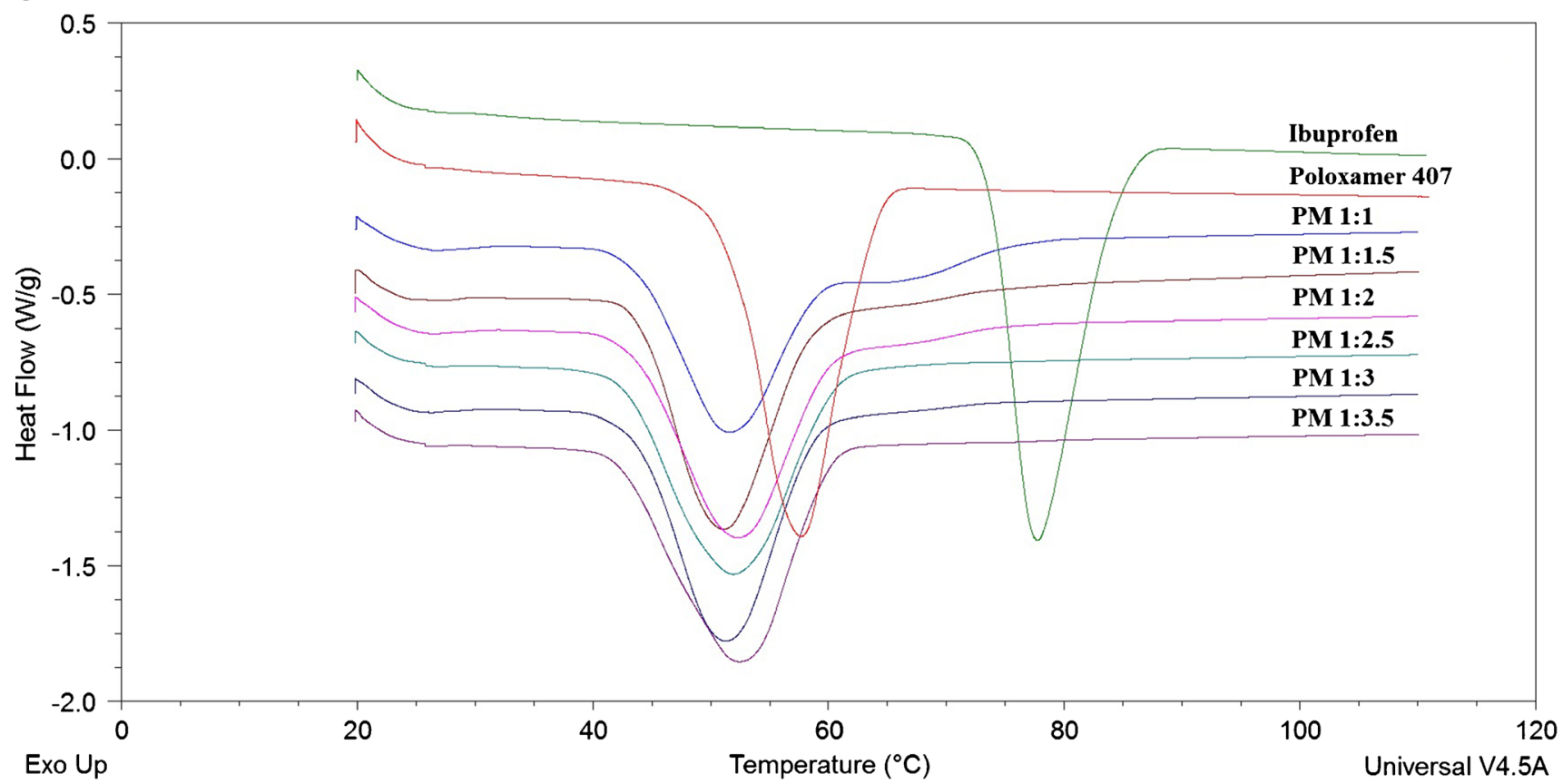

d

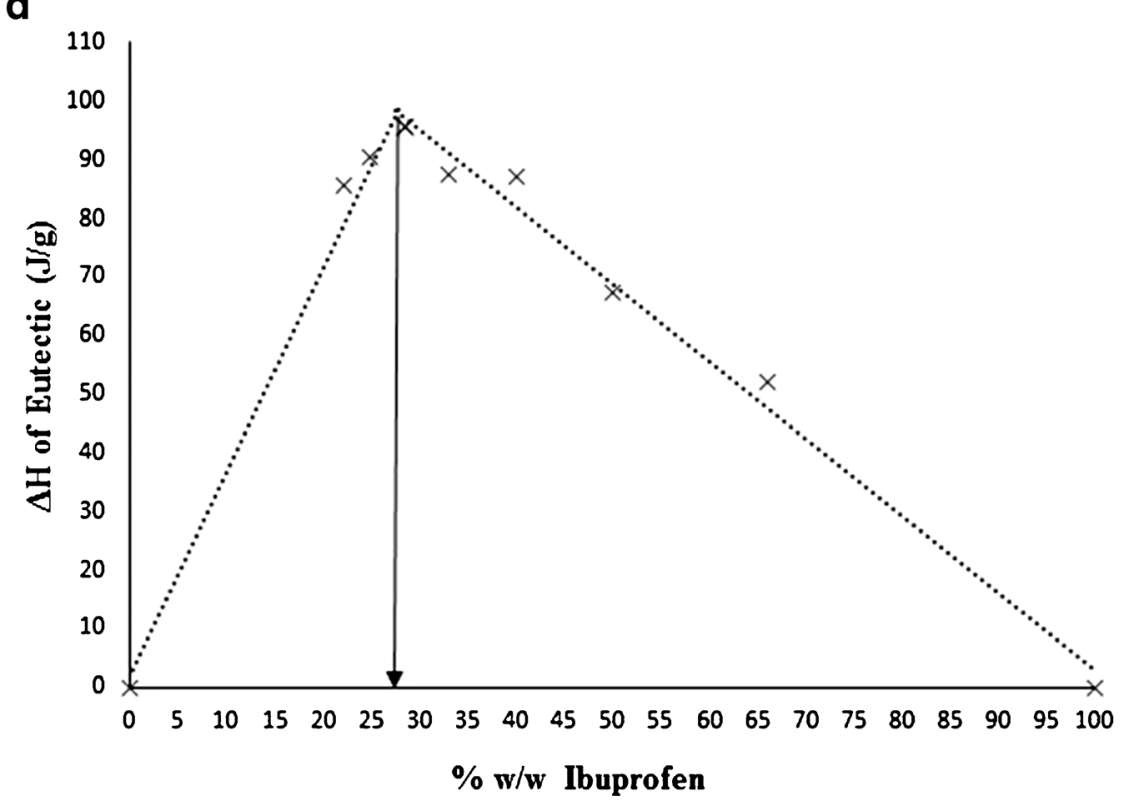

Fig. 7 continued.

The Carr's indices (24.42 to 17.60), Angle of repose (32.34 to 27.64), and Hausner ratio (1.324 to 1.210 ) values decreased with the increase in polymer content which were consistent with rheometer results.

\section{Modulated Differential Scanning Calorimetry}

Thermal analysis showed a characteristic behavior of the drug and polymer mixture. Figure 7 a shows the thermograms of drug, polymer, and the PMs while Fig. 7b shows with the FMs. Melting point of drug and polymer was found to be 76.79 and $57.69^{\circ} \mathrm{C}$, respectively. In the mDSC curves of PMs and FMs, a characteristic peak was seen which had melting onset temperatures ( $\mathrm{T}_{\text {onset }}$ ) between 39 and $44^{\circ} \mathrm{C}$ and melting peak temperatures $\left(\mathrm{T}_{\text {peak }}\right.$ ) between 45 and $50^{\circ} \mathrm{C}$. Table IV represents the average $\Delta \mathrm{H}_{\text {melt }}, \mathrm{T}_{\text {onset }}$, and $\mathrm{T}_{\text {peak }}$ for all samples, and it was observed from the data that enthalpy change for the PMs and FMs is lower than that for the drug alone. Drug melting peak was slightly seen for the ratios $1: 1$ and 1:1.5, but for higher ratios, it is completely absent, and only the eutectic endotherm was observed. The characteristic eutectic endotherm with a melting temperature of around $50^{\circ} \mathrm{C}$ was observed for all PMs as seen in Fig. 7c. The intersection of the best fit lines in Fig. $7 \mathrm{~d}$ reveals the exact eutectic composition to be close to $27 \% \mathrm{w} / \mathrm{w}$ ibuprofen which corresponds roughly to $1: 2.5 \mathrm{w} / \mathrm{w}$ ratio. 
Table IV. Parameters Derived from Modulated Differential Scanning Calorimeter (mDSC)

\begin{tabular}{lrll}
\hline Sample & $\Delta \mathrm{H}_{\text {melt }}(\mathrm{J} / \mathrm{g})$ & $\mathrm{T}_{\text {onset }}\left({ }^{\circ} \mathrm{C}\right)$ & $\mathrm{T}_{\text {peak }}\left({ }^{\circ} \mathrm{C}\right)$ \\
\hline Ibuprofen & $123.01 \pm 1.26$ & $72.69 \pm 2.59$ & $76.69 \pm 1.68$ \\
Poloxamer 407 & $116.05 \pm 0.86$ & $51.73 \pm 0.59$ & $57.69 \pm 1.33$ \\
PM 1:0.25 & $39.72 \pm 0.67$ & $43.88 \pm 0.82$ & $49.62 \pm 0.87$ \\
PM 1:0.5 & $52.21 \pm 1.48$ & $42.61 \pm 0.49$ & $49.68 \pm 0.24$ \\
PM 1:0.75 & $77.08 \pm 0.76$ & $43.34 \pm 0.82$ & $49.03 \pm 2.13$ \\
PM 1:1 & $67.30 \pm 0.51$ & $43.64 \pm 074$ & $51.27 \pm 1.36$ \\
PM 1:1.5 & $86.97 \pm 0.84$ & $44.16 \pm 0.51$ & $51.02 \pm 0.69$ \\
PM 1:2 & $87.32 \pm 1.31$ & $43.62 \pm 084$ & $52.15 \pm 1.24$ \\
PM 1:2.5 & $95.52 \pm 0.59$ & $43.03 \pm 0.48$ & $51.95 \pm 0.86$ \\
PM 1:3 & $90.36 \pm 1.02$ & $43.78 \pm 1.01$ & $51.29 \pm 1.84$ \\
PM 1:3.5 & $85.63 \pm 0.86$ & $42.42 \pm 0.55$ & $52.50 \pm 1.45$ \\
FM 1:0.25 & $24.84 \pm 1.08$ & $40.10 \pm 1.49$ & $45.00 \pm 1.77$ \\
FM 1:0.5 & $45.61 \pm 1.39$ & $39.70 \pm 1.03$ & $45.90 \pm 1.63$ \\
FM 1:0.75 & $56.76 \pm 2.09$ & $41.15 \pm 1.88$ & $45.74 \pm 0.72$ \\
\hline
\end{tabular}

\section{X-Ray Powder Diffraction Studies}

Figure 8a shows X-ray diffraction patterns of the drug and PMs whereas Fig. 8b shows for the drug and FMs. In all samples, the characteristic crystalline peaks of ibuprofen were seen although the intensities were lower than the drug.

\section{Fourier Transform Infrared Spectroscopy}

Figure 9 shows an overlay of FTIR spectra of all samples. In all the spectra, the characteristic peaks of ibuprofen can be seen. All the samples showed the characteristic $\mathrm{C}=\mathrm{O}$ stretching at around $1700 \mathrm{~cm}^{-1}$ observed for carboxylic acids. Also, a peak was seen in the region of around $3000 \mathrm{~cm}^{-1}$ for the $\mathrm{O}-\mathrm{H}$ group. The intensities were found to be lower than the drug itself for the samples after doing an addition spectra which could be due to the presence of the polymer giving rise to a dilution effect.

\section{DISCUSSION}

UV spectroscopy was done to establish a standard curve to analyze unknown concentrations of drug. Linear equation obtained from standard curve was used in the subsequent studies. Filter-binding studies on same standard solutions of drug revealed that there was no substantial binding to the filters being used which can be seen by the graph (postfiltration) in Fig. 2. It tells us that the filters can be used in the in vitro dissolution testing without having much errors by the dissolved drug getting bound to the filters.

Particle size distribution for all formulations was quite similar. Higher fractions of larger particles were observed due to waxy consistency of the molten polymer which gave rise to larger particles and lumps.

Assay of the prepared PMs and FMs was done to see if the blending parameters used and the conditions used to carry out the fusion process were optimal to have acceptable content uniformity. All formulations had uniform distribution of drug in each sample.

Effect of the polymer present physically as well as when molecularly dispersed on saturation solubility of ibuprofen was evaluated in the saturation solubility studies. Solubility enhancement is one of the key parameters governing the drug's performance after oral ingestion in terms of its dissolution in body fluids. In the current study, maximum solubility enhancement was observed in acidic media, and this was critical because ibuprofen, being a weak acidic drug, remains mostly unionized in acidic $\mathrm{pH}$ which is the insoluble form. Physical presence of polymer in the PMs also had a similar effect, but it was marginally less than the corresponding FMs. From these studies, it can be concluded that the saturation solubility of the drug was enhanced mainly due to the Poloxamer 407 presence in the micellar form and the fusion process gave it a marginal boost.

Phase solubility studies gave a good indication about the mechanism and stoichiometry involved in the micellar solubilization of ibuprofen at different concentrations of Poloxamer 407 above its critical micellar concentration. Studies have suggested an umbrella like configuration of Poloxamer 407 micelles (38).

Enhanced dissolution of the PMs and FMs as compared to the drug was observed. Intrinsic or saturation solubility of drug and its dissolution are two different processes. Although dissolution behavior of any dosage form depends a lot on the former parameter, dissolution is a kinetic phenomenon whereas saturation solubility is a thermodynamic phenomenon. By saying kinetic phenomenon, it means that dissolution behavior depends on how a drug molecule after getting solubilized bypasses the diffusion layer of saturated drug solution into the bulk media and remain solubilized there until it gets absorbed (39). Complete release of the drug was expected in $\mathrm{pH} 7.2$ as the drug is weakly acidic and, hence, remains ionized in basic $\mathrm{pH}$. The formulations showed significant enhancement in dissolution rates in acidic media and de-ionized water. Another important thing to note was the dissolution behavior of ibuprofen which showed a classic spring and parachute effect where the diffused drug crystallizes out in the bulk media, and percent release goes down with time. Such an effect was not seen in the formulations which might be due to the micellar effect of Poloxamer 407 helping the drug to remain solubilized. At low concentrations, they form monomolecular micelles in which the hydrophobic core of propylene oxide acts as a drug reservoir, and the hydrophilic ethylene oxide portion reduces the interfacial tension between the reservoir and aqueous media $(22,38,40)$. This amphiphilic nature enhances the solubility of drugs and also helps to avoid its crystallization after diffusing through the saturated drug layer into the bulk solution $(20,41)$. From the dissolution data, it was noticed that though there was not much difference in saturation solubility values between PMs and FMs seen previously, there was significant difference in their dissolution profiles.

To check whether the observed difference in the dissolution rates was significant, statistical tests were performed. As a rule of thumb, higher MDT values indicate slower drug release, and reverse is true for the MDR values. MDT values were not so discriminating among samples, and the reason for that could be the spring and parachute effect seen in acidic media and de-ionized water for the drug and, hence, the negative values. On the other hand, MDR values suggested that the formulations had higher drug releasing capacities with FM 1:0.75 being the highest for all media. In the pair-wise analysis, $f_{1}$ values give an idea 
a

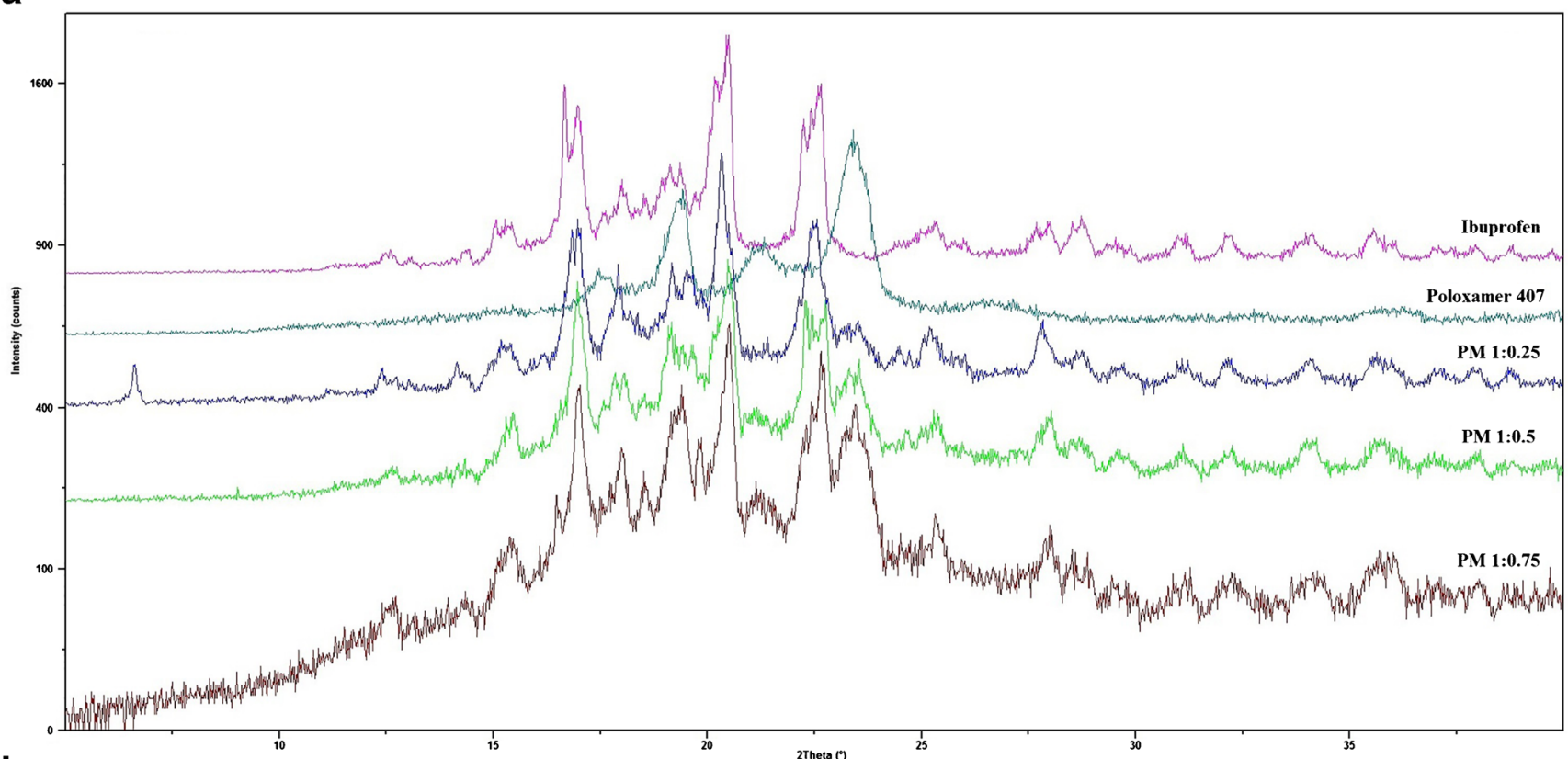

b

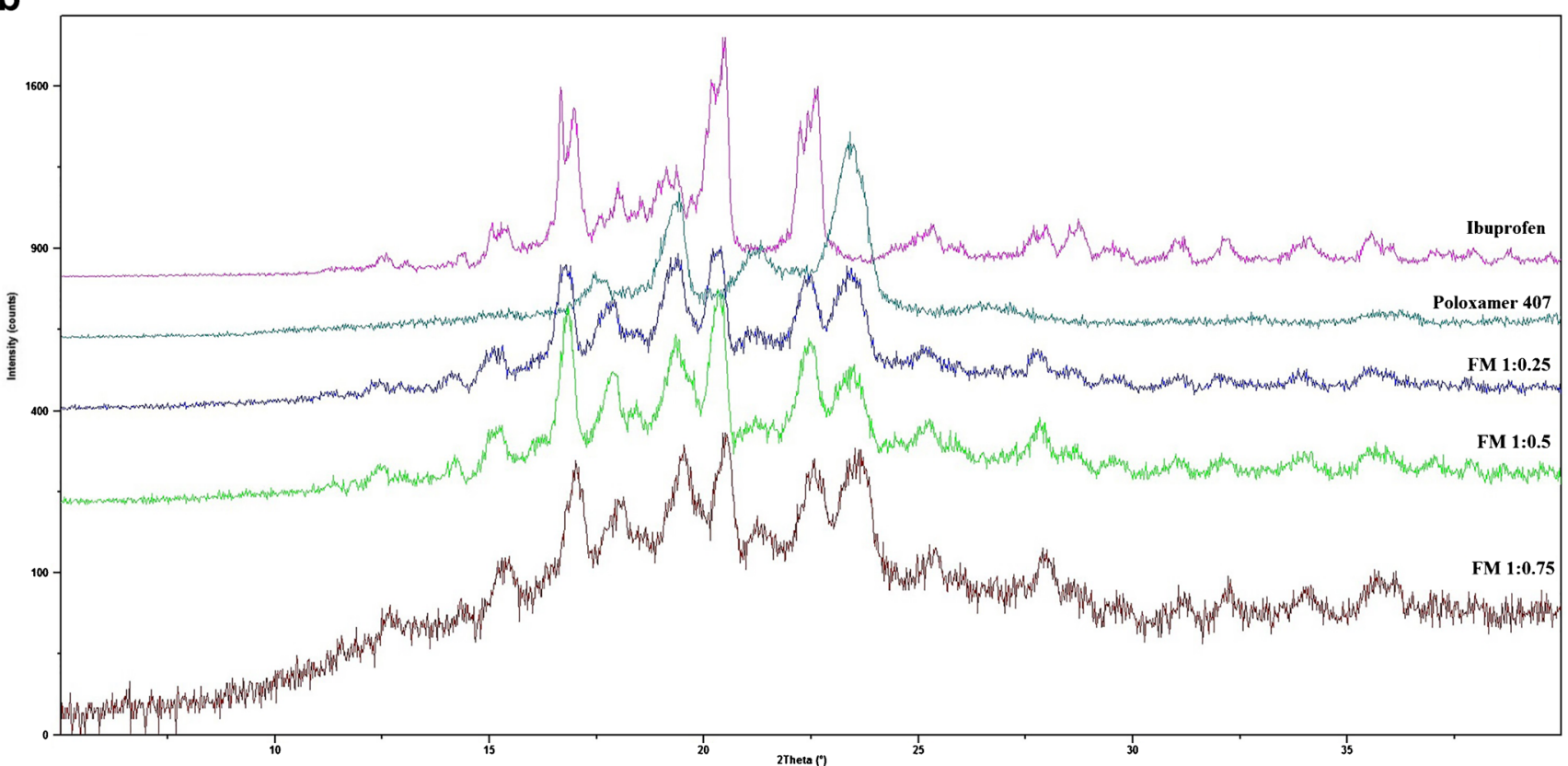

Fig. 8. Overlay of X-ray diffraction patterns between a ibuprofen and physical mixtures (PM); b ibuprofen and fusion mixtures (FM)

of approximate value of percent error between dissolution profiles with a value of $0-15$ indicating no difference and dissimilarity increasing proportionately with the value. FDA recommends $f_{2}$ values of 50-100 ensure dissolution data equivalence with a value of 100 indicating complete similarity and values below 50 suggesting non-equivalence (42). From the pair-wise analysis, the statistical non-equivalence of the dissolution profiles of formulations when compared to the drug was evident. Observed $p$ values from ANOVAbased methods showed that the difference in the dissolution profile at each time point was statistically significant for all media $(p<0.05)$. The calculated $F$ values were greater than $F_{\text {critical }}$ for all samples. Post-hoc tests were done to compare each sample among themselves individually. As seen from the two-tail $p$ values of the post-hoc $t$ tests, the difference in dissolution profile between PM (1:0.75) and FM (1:0.75) was statistically significant in acidic media and de-ionized water but not in phosphate buffer $(p<0.05)$ showing that the fusion process enhanced dissolution rate to a statistically significant extent.

Powder flow behavior during a process in manufacturing depends on a lot of factors like the densities of powder, particle size distribution, moisture content, morphology of the particles, etc. (43). Complete understanding of all these parameters is necessary to avoid issues during the manufacturing cycle. Conventional methods like Carr's index, Angle of repose, and Hausner ratio have been used traditionally for understanding the flow properties. Powder rheometer used in 


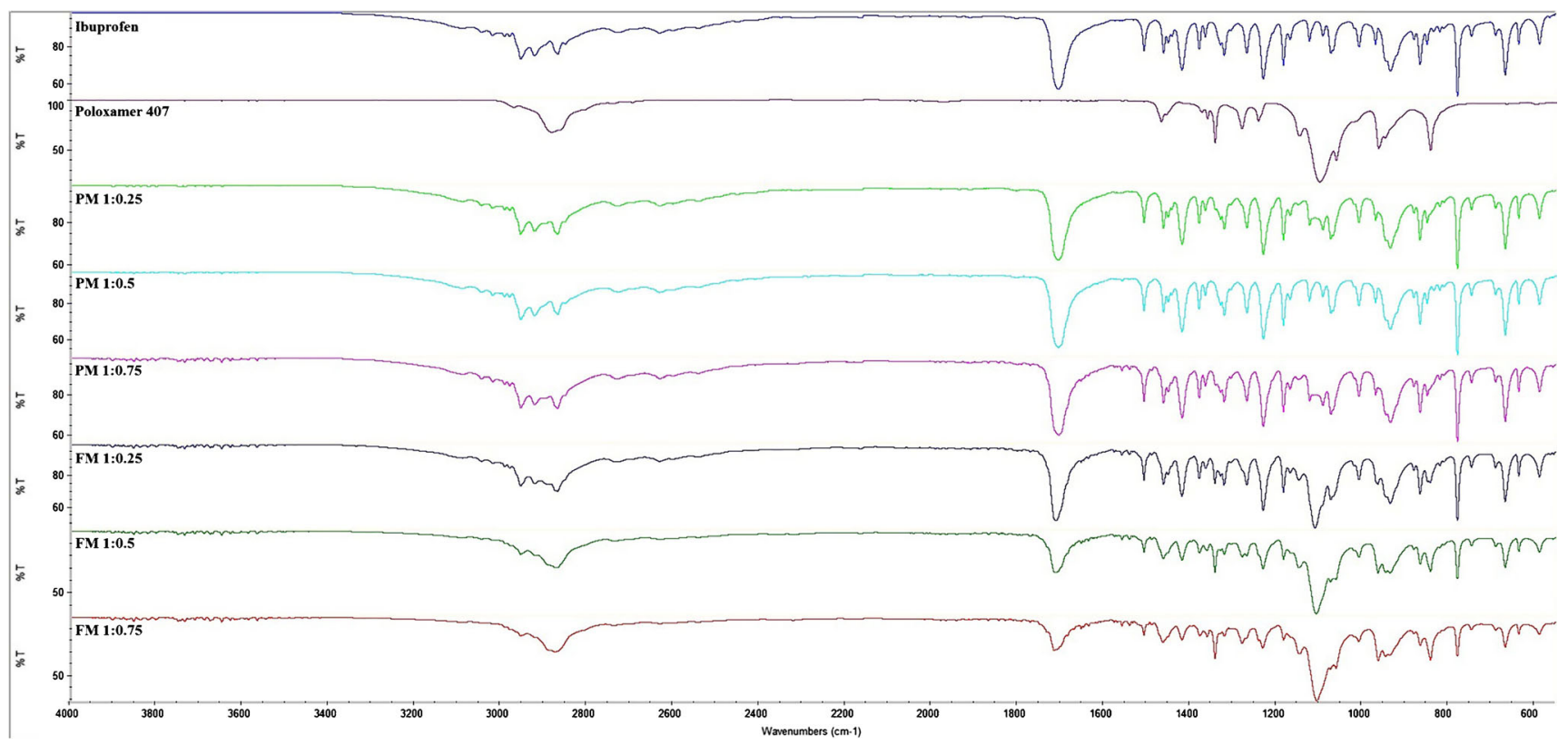

Fig. 9. Overlay of Fourier transform infrared spectroscopy spectra of ibuprofen, physical (PM), and fusion mixtures (FM)

this study provides a sophisticated, accurate, and sensitive measurement for the energies required for powders to flow under certain conditions. As can be seen, the BFE values decreased with the polymer content and simple explanation for that is the waxy nature of Poloxamer 407 which acts a lubricant (44), and hence, less energy is required for powder flow. Hausner ratio of 1.25 and higher indicates poor flow, and almost all the formulations along with the drug fell in that range except for FM 1:0.75 which was in the free flowing range which was consistent with rheometer data. Similar observations were made by the Carr's index and angle of repose values. There was not much difference in regard to densities (bulk) for the different formulations.

Solid state characterization techniques like mDSC, XRD, and FTIR were employed to evaluate the interactions and changes of drug in the formulations. The characteristic peak seen in the mDSC curves which was lower than the individual melting temperatures of the drug as well as polymer indicated formation of a eutectic for the given ratios (9). From the curves, it was also seen that the crystalline peak for ibuprofen diminished with the increasing polymer content. A ratio of $1: 2.5 \mathrm{w} / \mathrm{w}$ was found to be the eutectic composition between drug and polymer. But from a practical standpoint, this ratio does not allow for drug delivery at an acceptable target weight for the formulation. With this ratio, delivery of $200 \mathrm{mg}$ ibuprofen would end up having a formulation weight of $700 \mathrm{mg}$ without excipients which is not feasible.

Diffraction studies were performed to check the sustainability of crystalline nature of the drug after the fusion process. All PMs and FMs showed characteristic crystalline peaks of ibuprofen, but their intensities were lower and that can be due to the dilution effect. These studies prove that the observed dissolution rate enhancement might not be due to any changes in the crystallinity of ibuprofen which means the drug dissolution was enhanced when the drug was in more stable crystalline form.

The main purpose of performing FTIR spectroscopy was to observe if there was any molecular interaction between drug and polymer in terms of new bond formation or existing bond modifications. Any new characteristic peak could not be seen from the FTIR spectra which confirms that chemical nature of ibuprofen was intact in the formulation. It also indicates that the changes in solubility and dissolution rates were due to the micellar solubilization effect and not any chemical modification.

\section{CONCLUSION}

Observations of this work portray the potential of Poloxamer 407 in solubility and dissolution rate enhancement of poorly soluble drugs like ibuprofen used here. Solid state characterization techniques like mDSC suggests the formation of eutectic mixture between drug and polymer. XRD and FTIR data indicates that the drug was present in the stable crystalline form. Moreover, the polymer ratios selected for the current study allows for practical applications of the findings in terms of delivering the drug with an acceptable target tablet weight.

\section{ACKNOWLEDGMENTS}

The authors are thankful to Division of Pharmaceutical Sciences, Long Island University to provide an opportunity to conduct the above research.

\section{COMPLIANCE WITH ETHICAL STANDARDS}

Conflict of Interest

The authors declare that they have no competing interests.

\section{REFERENCES}

1. Hu L, Tang X, Cui F. Solid lipid nanoparticles (SLNs) to improve oral bioavailability of poorly soluble drugs. J Pharm Pharmacol. 2004;56(12):1527-35. 
2. Dave RH, Patel AD, Donahue E, Patel HH. To evaluate the effect of addition of an anionic surfactant on solid dispersion using model drug indomethacin. Drug Dev Ind Pharm. 2012;38(8):930-9.

3. Murdande SB, Shah DA, Dave RH. Impact of nanosizing on solubility and dissolution rate of poorly soluble pharmaceuticals. J Pharm Sci. 2015;104(6):2094-102.

4. Goud NR, Suresh K, Sanphui P, Nangia A. Fast dissolving eutectic compositions of curcumin. Int J Pharm. 2012;439(1-2):63-72.

5. Tao Q, Chen J-M, Ma L, Lu T-B. Phenazopyridine cocrystal and salts that exhibit enhanced solubility and stability. Cryst Growth Des. 2012;12(6):3144-52.

6. Singhal D, Curatolo W. Drug polymorphism and dosage form design: a practical perspective. Adv Drug Deliv Rev. 2004;56(3):335-47.

7. Özdemir N, Erkin J. Enhancement of dissolution rate and bioavailability of sulfamethoxazole by complexation with $\beta$-cyclodextrin. Drug Dev Ind Pharm. 2012;38(3):331-40.

8. Djekic L, Primorac M, Filipic S, Agbaba D. Investigation of surfactant/cosurfactant synergism impact on ibuprofen solubilization capacity and drug release characteristics of nonionic microemulsions. Int J Pharm. 2012;433(1):25-33.

9. Passerini N, Albertini B, González-Rodríguez ML, Cavallari C, Rodriguez L. Preparation and characterisation of ibuprofenpoloxamer 188 granules obtained by melt granulation. Eur J Pharm Sci. 2002;15(1):71-8.

10. Kolašinac N, Kachrimanis K, Homšek I, Grujić B, Đurić Z, Ibrić $\mathrm{S}$. Solubility enhancement of desloratadine by solid dispersion in poloxamers. Int J Pharm. 2012;436(1):161-70.

11. Guyot M, Fawaz F, Bildet J, Bonini F, Lagueny A-M. Physicochemical characterization and dissolution of norfloxacin/ cyclodextrin inclusion compounds and PEG solid dispersions. Int J Pharm. 1995;123(1):53-63.

12. Vippagunta SR, Wang Z, Hornung S, Krill SL. Factors affecting the formation of eutectic solid dispersions and their dissolution behavior. J Pharm Sci. 2007;96(2):294-304.

13. Serajuddin A. Solid dispersion of poorly water-soluble drugs: early promises, subsequent problems, and recent breakthroughs. J Pharm Sci. 1999;88(10):1058-66.

14. Obaidat AA, Obaidat RM. Controlled release of tramadol hydrochloride from matrices prepared using glyceryl behenate. Eur J Pharm Biopharm. 2001;52(2):231-5.

15. Huber HE, Dale LB, Christenson GL. Utilization of hydrophilic gums for the control of drug release from tablet formulations I. Disintegration and dissolution behavior. J Pharm Sci. 1966;55(9):974-6.

16. Miyagawa Y, Okabe T, Yamaguchi Y, Miyajima M, Sato H, Sunada H. Controlled-release of diclofenac sodium from wax matrix granule. Int J Pharm. 1996;138(2):215-24.

17. Castro SG, Sanchez Bruni SF, Urbizu LP, Confalonieri A, Ceballos L, Lanusse CE, et al. Enhanced dissolution and systemic availability of albendazole formulated as solid dispersions. Pharm Dev Technol. 2013;18(2):434-42.

18. Cabana A, Aitt-Kadi A, Juhász J. Study of the gelation process of polyethylene oxide a-polypropylene oxide b-polyethylene oxide a copolymer (Poloxamer 407) aqueous solutions. J Colloid Interface Sci. 1997;190(2):307-12.

19. Savić R, Eisenberg A, Maysinger D. Block copolymer micelles as delivery vehicles of hydrophobic drugs: micelle-cell interactions. J Drug Target. 2006;14(6):343-55.

20. Dumortier G, Grossiord JL, Agnely F, Chaumeil JC. A review of poloxamer 407 pharmaceutical and pharmacological characteristics. Pharm Res. 2006;23(12):2709-28.

21. Urbán-Morlán Z, Castro-Ríos R, Chávez-Montes A, MelgozaContreras LM, Piñón-Segundo E, Ganem-Quintanar A, et al. Determination of poloxamer 188 and poloxamer 407 using highperformance thin-layer chromatography in pharmaceutical formulations. J Pharm Biomed Anal. 2008;46(4):799-803.

22. Newa M, Bhandari KH, Li DX, Kwon T-H, Kim JA, Yoo BK, et al. Preparation, characterization and in vivo evaluation of ibuprofen binary solid dispersions with poloxamer 188. Int J Pharm. 2007;343(1-2):228-37.

23. Filippa MA, Gasull EI. Ibuprofen solubility in pure organic solvents and aqueous mixtures of cosolvents: interactions and thermodynamic parameters relating to the solvation process. Fluid Phase Equilib. 2013;354:185-90.

24. Stewart DW, Ragg PG, Sheppard S, Chalkiadis GA. The severity and duration of postoperative pain and analgesia requirements in children after tonsillectomy, orchidopexy, or inguinal hernia repair. Pediatr Anesth. 2012;22(2):136-43.

25. Bellantone RA, Patel P, Sandhu H, Choi DS, Singhal D, Chokshi $\mathrm{H}$, et al. A method to predict the equilibrium solubility of drugs in solid polymers near room temperature using thermal analysis. J Pharm Sci. 2012;101(12):4549-58.

26. Adjei A, Newburger J, Martin A. Extended hildebrand approach: solubility of caffeine in dioxane-water mixtures. J Pharm Sci. 1980;69(6):659-61.

27. Marsac PJ, Li T, Taylor LS. Estimation of drug-polymer miscibility and solubility in amorphous solid dispersions using experimentally determined interaction parameters. Pharm Res. 2009;26(1):139-51.

28. Badawy SIF, Menning MM, Gorko MA, Gilbert DL. Effect of process parameters on compressibility of granulation manufactured in a high-shear mixer. Int $\mathrm{J}$ Pharm. 2000;198(1):51-61.

29. Pandey P, Tao J, Chaudhury A, Ramachandran R, Gao JZ, Bindra DS. A combined experimental and modeling approach to study the effects of high-shear wet granulation process parameters on granule characteristics. Pharm Dev Technol. 2013;18(1):210-24.

30. Marques HC, Hadgraft J, Kellaway I. Studies of cyclodextrin inclusion complexes. I. The salbutamol-cyclodextrin complex as studied by phase solubility and DSC. Int J Pharm. 1990;63(3):259-66.

31. Loftsson T, Brewster ME. Cyclodextrins as functional excipients: methods to enhance complexation efficiency. J Pharm Sci. 2012;101(9):3019-32.

32. Pillay V, Fassihi R. Evaluation and comparison of dissolution data derived from different modified release dosage forms: an alternative method. J Control Release. 1998;55(1):45-55.

33. Asare-Addo K, Conway BR, Hajamohaideen MJ, Kaialy W, Nokhodchi A, Larhrib H. Aqueous and hydro-alcoholic media effects on polyols. Colloids Surf B: Biointerfaces. 2013;111:24-9.

34. Abioye AO, Kola-Mustapha A, Chi GT, Ilya S. Quantification of in situ granulation-induced changes in pre-compression, solubility, dose distribution and intrinsic in vitro release characteristics of ibuprofen-cationic dextran conjugate crystanules. Int J Pharm. 2014;471(1-2):453-77.

35. Moore JW, Flanner HH. Mathematical comparison of dissolution profiles. Pharm Technol. 1996;20(6):64-74.

36. Mauger JW, Chilko D, Howard S. On the analysis of dissolution data. Drug Dev Ind Pharm. 1986;12(7):969-92.

37. Dugar RP, Dave RH. To study the effects of solvent and relative humidity on rheological and thermal properties of microcrystalline cellulose granules using hydroxypropyl methylcellulose as binder. Int J Pharm Sci Res. 2014;5(9):3616.

38. Chiappetta DA, Sosnik A. Poly(ethylene oxide)-poly(propylene oxide) block copolymer micelles as drug delivery agents: improved hydrosolubility, stability and bioavailability of drugs. Eur J Pharm Biopharm. 2007;66(3):303-17.

39. Costa P, Sousa Lobo JM. Modeling and comparison of dissolution profiles. Eur J Pharm Sci. 2001;13(2):123-33.

40. Cafaggi S, Russo E, Caviglioli G, Parodi B, Stefani R, Sillo G, et al. Poloxamer 407 as a solubilising agent for tolfenamic acid and as a base for a gel formulation. Eur J Pharm Sci Off J Eur Fed Pharm Sci. 2008;35(1-2):19-29.

41. Kabanov AV, Batrakova EV, Alakhov VY. Pluronic ${ }^{\circledR}$ block copolymers as novel polymer therapeutics for drug and gene delivery. J Control Release. 2002;82(2):189-212.

42. Yuksel N, Kanık AE, Baykara T. Comparison of in vitro dissolution profiles by ANOVA-based, model-dependent and independent methods. Int J Pharm. 2000;209(1-2):57-67.

43. Dugar RP, Gupta P, Dave RH. Effect of relative humidity on acetaminophen tablet properties prepared by different techniques using polyvinylpyrrolidine derivatives as binder.

44. Desai D, Zia H, Quadir A. Evaluation of selected micronized poloxamers as tablet lubricants. Drug Deliv. 2007;14(7):413-26. 